2. Fan L, Yang H, Yu L, Wang Z, Ye J, Zhao H, et al. Multicenter, prospective, observational study of a novel technique for preoperative pulmonary nodule localization. J Thorac Cardiovasc Surg. 2020;160: 532-9.e2.
3. Hwang S, Kim TG, Song YG. Comparison of hook wire versus coil localization for video-assisted thoracoscopic surgery. Thorac Cancer. 2018;9:384-9.

4. Lin MW, Chen JS. Image-guided techniques for localizing pulmonary nodules in thoracoscopic surgery. J Thorac Dis. 2016;8:S749-55.
See Article page 532.

\section{Commentary: One more way to skin the cat}

\author{
Waël C. Hanna, MDCM, MBA, FRCSC
}

Hardly a day goes by in the practice of a thoracic surgeon without an encounter with a small, nonpalpable, and nonvisible lung nodule. Because these early lesions become the new norm of practice, having effective localization methods becomes an important consideration for both the surgeon and the patient.

In this clinical trial, the authors address what they perceive is a deficiency in intraoperative nodule localization methods. ${ }^{1}$ They present a safety and feasibility study for a new 4-pronged localization device. The logistics of the operation are quite similar to nodule localization by microcoil. A fiducial marker is placed in the vicinity of the nodule by an interventional radiologist under computed tomography guidance, and this is followed by a wedge resection to remove the lesion and the marker.

There are 2 notable differences between this new technique and microcoil localization. First is the fact that with this new device, a string is left hanging from the pleural surface to mark the location of the marker. Second, the marker itself is palpable after lung deflation, thereby obviating the need for intraoperative fluoroscopic confirmation.

In this single-arm prospective trial, the authors demonstrate a high rate of success $(96.7 \%)$ and an acceptable safety profile. The trial did not have a comparator arm,

From the Division of Thoracic Surgery, McMaster University, Hamilton, Ontario, Canada.

Disclosures: Author has nothing to disclose with regard to commercial support.

Received for publication Nov 1, 2019; revisions received Nov 1, 2019; accepted for publication Nov 1, 2019; available ahead of print Nov 27, 2019.

Address for reprints: Waël C. Hanna, MDCM, MBA, FRCSC, St Joseph's Healthcare Hamilton, 50 Charlton Ave. E, Juravinski Tower, Suite T2105 F, Hamilton, Ontario, Canada L8N4A6 (E-mail: hannaw@mcmaster.ca).

J Thorac Cardiovasc Surg 2020;160:542-3

$0022-5223 / \$ 36.00$

Copyright (c) 2019 by The American Association for Thoracic Surgery

https://doi.org/10.1016/j.jtcvs.2019.11.026

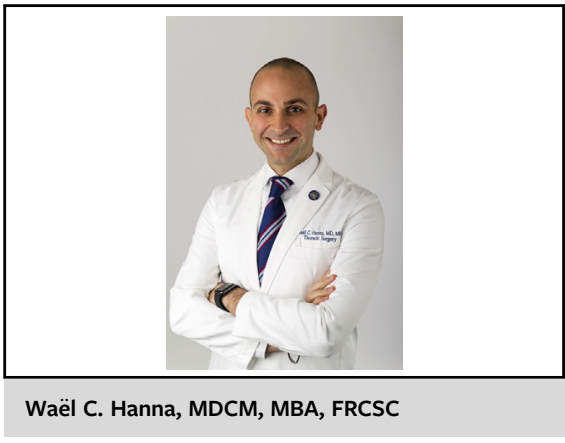

CENTRAL MESSAGE

The armamentarium of pulmo-

nary nodule localization is being

enriched by new techniques, and

this is important for the evolu-

tion of thoracic surgery.

but the authors nonetheless state that it performs better than the historical localization technique (hookwire) at their center. It is interesting that most failed cases were in the early phase of this trial, potentially pointing to a smooth learning curve. The authors also state that this device can correct the problem of fiducial dislodgement, due to the 4-pronged design, but they do not discuss displacement rates of other devices. They also state that the design of this device facilitates anatomic segmental resection, but how this could be achieved is unclear from the data and the discussion.

This new device joins a litany of others that have been reported previously, and it operates on many of the same principles. Nonetheless, this work is important because it adds one more tool to the ever-expanding armamentarium of pulmonary nodule localization techniques. The authors suggest that a randomized controlled trial is required to compare their new approach to hookwire or other techniques. I am not sure this would be required. The preference for the localization technique is highly dependent on the operator's skill set and 
available equipment, funding, and resources. Individual centers will gravitate to the technique that works best in their environment. There are many ways to skin a cat, and that is not necessarily a bad thing.

\section{Reference}

1. Fan L, Yang H, Yu L, Wang Z, Ye J, Zhao H, et al. Multicenter, prospective observational study of a novel technique for preoperative pulmonary nodule localization. J Thorac Cardiovasc Surg. 2020;160:532-9.e2. 